\title{
Effects of voluntary and involuntary mediation on estimates of short time intervals
}

\author{
ELVIS C. JONES AND RICHARD L. NARVER \\ TEXAS CHRISTIAN UNIVERSITY
}

Subjects estimated $5 \mathrm{sec}$, and $20 \mathrm{sec}$. intervals via the method of production or reproduction. Different groups of $S s$ were either given no instructions as to the bases on which to estimate, were told to count their pulses, or were instructed to orally count "one-thousand-one, one-thousane-two, etc." Subjects were trained with and without knowledge of results. Correlations between group means over trials suggest that the method of production may be mediated by involuntary processes, but that reproduction of $20 \mathrm{sec}$. intervals may be mediated by other processes.

Methods of time estimation have been classified into three general categories by Bindra \& Waksberg (1956): verbal estimation, where the $S$ verbally estimates the duration of an interval produced by $\mathrm{E}$; production, where the $S$ produces an interval of a duration verbally specified by E; and reproduction, where the S produces an interval of the same apparent duration as an interval previously produced by $\mathbf{E}$.

There is evidence that these methods do not measure the same process. Clausen (1950), and Siegman (1962), for example, have found that verbal estimation and production are reliable, but that reproduction is not. These investigators have also found that the methods are relatively uncorrelated. Hawkes, Joy, \& Evans (1962), found that drugs which affect respiration rate affect estimates by production, but not reproduction.

The present Es felt that useful distinctions can be made on the basis of possible voluntary vs. involuntary mediation underlying short interval time estimation. It is possible that one process consists of mediation via rhythmic involuntary responses. This would require little in the way of retention, and would be fairly reliable over time. The method of production was hypothesized to involve this type of mediation.

Another possible mediation would be via feedback from voluntary responses (e.g. implicit counting, finger tapping, etc.). This would probably involve a difficult memory requirement since Ss would have to somehow remember the rate of counting as well as the number of counts which correspond to an interval. This type of mediation would probably be less reliable than involuntary mediation. The method of reproduction was hypothesized to involve this type of mediation.

The hypothesized sources of mediation were not assumed to be intrinsically associated with specific estimation ethods. Some Ss may use both methods concurrently. However, the naive $\mathrm{S}$ was expected to use one mediation technique when producing, and another technique when reproducing intervals. It was also assumed that Ss may not be able to accurately verbalize the specific mediation they use, and may even give verbal reports that contradict the evidence.

In the present experiment, Ss were instructed to use specific mediation techniques while estimating via production or reproduction. The mediation techniques were intended to force the Ss to attend to voluntary or involuntary processes. Two intervals were used to test for the effects of imposing differing memory requirements. Variability in performance was intentionally introduced by giving, then withdrawing, knowledge of results.

\section{Method}

The Ss were 60 volunteer students enrolled in introductory psychology courses, randomly assigned to the cells of a 2 by 3 by 2 factorial design. The factors and levels were: Method (production/reproduction), Mediation (none specified/counting pulses/voluntary counting), and Intervals (5 sec/20 sec).

Times were recorded (within hundredths of seconds) by a Standard Timer. The timer was activated by a hand switch held by the S. All Ss were given 10 trials, each of the first five trials followed by the $E$ telling the $S$ that his estimate was "toolong," "too short," or "correct." On the last five trials, the Ss were not given knowledge of results. Intertrial intervals were approximately 10 sec. on all trials. Ss were run individually.

Ss in the groups using the method of production and reproduction were divided into the following subgroups: N5-Ss estimated a 5 sec. interval, and were not instructed to use any specific mediation technique. N20-same as N5, except that Ss estimated a $20 \mathrm{sec}$. interval. P5-Ss estimated a 5 sec. interval, and were instructed to estimate by counting their pulses. P20same as P5, except that a 20 sec. interval was estimated. C5-Ss estimated a $5 \mathrm{sec}$. interval, and were told to count "one-thousand-one, one-thousand-two, etc." C20-same as $\mathrm{C} 5$, except that a $20 \mathrm{sec}$. interval was estimated.

Groups estimated by the method of production by turning the hand switch on, waiting until they thought that the interval (5 or 20 sec.) specified by the $\mathrm{E}$ had passed, then turning the switch off. Groups estimating by the method of reproduction attempted to match the duration of a standard interval produced by the $\mathrm{E}$ prior to each trial. The standard interval consisted of two clicks separated by 5 or $20 \mathrm{sec}$. The S performed by turning the hand switch on for the same apparent duration as the standard interval before turning it off. Results and Discussion

Group means, based on algebraic sums of errors, were correlated over all trials. Among groups producing 
a 5 sec, interval, the correlations were $\mathrm{N} 5 / \mathrm{P} 5=.94$, $\mathrm{N} 5 / \mathrm{C} 5=.01, \mathrm{P} 5 / \mathrm{C} 5=.16$. Among production groups estimating $20 \mathrm{sec}$, the correlations were: $\mathrm{N} 20 / \mathrm{P} 20=.41$, $\mathrm{N} 20 / \mathrm{C} 20=.48, \mathrm{P} 20 / \mathrm{C} 20=.07$. With $8 \mathrm{df}, \mathrm{r}=.55$ is significant at $<.05$, using a one-tailed test. These results indicate that a 5 sec., mediation via pulse counting is most similar to production without instruction, and mediation via voluntary counting bears no relation. At $20 \mathrm{sec} .$, mediation by pulse counting and via voluntary counting are both similar to production without instruction, suggesting that at that interval, production without instruction may involve attention to both voluntary and involuntary processes. The correlations, however, were not statistically significant. In both $5 \mathrm{sec}$. and $20 \mathrm{sec}$. estimations, the correlation between groups counting pulses and voluntary count groups are low, indicating that although both mediation techniques involve counting, they are nevertheless quite different.

Among groups reproducing $5 \mathrm{sec}$. intervals, the correlations were: $\mathrm{N} 5 / \mathrm{P} 5=-.69, \mathrm{~N} 5 / \mathrm{C} 5=-.05, \mathrm{P} 5 / \mathrm{C} 5=$ .07. Among reproduction groups estimating $20 \mathrm{sec}$, the correlations were: $\mathrm{N} 20 / \mathrm{P} 20=.12, \mathrm{~N} 20 / \mathrm{C} 20=-.10, \mathrm{P} 20 /$ $\mathrm{C} 20=-.22$. The N5/P5 correlation is sufficiently high to indicate that reproduction at $5 \mathrm{sec}$. may be mediated by attending to involuntary processes, although the relationship may be negative. At both 5 and $20 \mathrm{sec}$. mediation by voluntary counting seems uncorrelated with reproduction without instruction, and at both intervals pulse counting and voluntary counting seem to be uncorrelated.

The correlation between the production N5 group and the reproduction N5 group was .49 , and the correlation between the production N20 group and the reproduction N20 group was -.64, suggesting that possibly one or both of the methods involve different mediation at different intervals. Some light is thrown on this question by the correlation between the production $\mathrm{N} 5$ and N20 groups $(r=.48)$, and between the reproduction N5 and N20 groups $(r=-.16)$. These correlations suggest that with different intervals, production may still involve the same mediational process, whereas reproduction may involve different processes at the different intervals.

The data indicate that the hypothesized relationship between involuntary processes and the method of production may be correct. The hypothesized relationship between voluntary processes and the method of reproduction, however, was not supported by the data. In fact, mediation via involuntary processes seems more reasonable at a 5 sec. interval.

The experimental treatments do not, of course, exhaust the possible voluntary and involuntary processes which are, or could be used in estimating short time intervals. This general approach, suggested by Spivack \& Levine (1964), nevertheless seems to be fruitful in analyzing performance on time estimation tasks.

\section{References}

Bindra, D., \& Waksberg, Helene. Methods and terminology in studies of time estimation. Psychol. Bull., 1956, 53, 155-159.

Clausen, J. An evaluation of experimental methods of time judgment. J. exp. Psychol., 1950, 40, 756-761.

Hawkes, G. R., Joy, R. J. T., \& Evans, W. o. Autonomic effects on estimation of time: evidence of a physiological correlate of temporal experience. J. Psychol., 1962, 53, 183-191.

Siegman, A. W. Intercorrelation of some measures of time estimation. Percept. mot. Skills, 1962, 14, 381-382.

Spivack, G., \& Levine, M. Consistency of individual differences in time judgments. Percept. mot. Skills, 1964, 19, 83-92. 